psychology to Einstein's process of thinking in the work that led to the theory of relativity (Wertheimer's work drew upon actual discussions with Einstein himself). Miller then goes on to a broader discussion in terms of new researches based on extensions of Piaget's work on genetic epistemology. Two different versions of genetic epistemology are considered here, the first due to Pylyshin and the second to Kosslyn. Pylyshin and Kosslyn are in agreement in that they develop detailed accounts of how imaginative thought actually proceeds and try to support these accounts on the basis of actual case-studies. Their principal disagreement is on the dynamic role of images. Roughly speaking, Kosslyn assigns a positive predictive power to images, while Pylyshin regards them, in effect, as little more than passive displays of abstract propositional thought.

Although Miller gives what seems to be a fair treatment of this whole subject, I feel that he fails to be adequately critical in that he accepts an assumption that seems to be taken for granted in all the work on genetic epistemology. This is that creativity is primarily to be understood through the development of knowledge, enriched perhaps from time to time by invention whose source is (along the lines indicated by Poincaré) ultimately in a mysterious intuition. I would like to suggest that while all of these factors are involved in creativity, its primary source is in perception, not only through the senses, but, even more, through the mind (as indicated by the Greek noesis and the German Vernunft, which latter means intuitive or perceptive reason). Kostler gives an example of this, in the sudden realization of Archimedes that the volume of water displaced by a body is the same as the volume of the body independently of the complex details of its shape. Perhaps we could say that Einstein must have similarly realized somehow that the problem with electrodynamics was essentially the same as with thermodynamics; that is, to find principles that are independent of a detailed dynamical description of all the complex processes that are actually at work in concrete experimental situations. It seems to me that a study of the history of the subject from such a perspective is necessary, if we are to have a proper account of how the mind gets out of the "rut" of thinking in terms of old concepts that have long been taken for granted.

I feel that in spite of certain inadequacies Professor Miller has made a valuable contribution to our understanding of creativity in twentieth-century physics. His book is well worth reading by all those who are interested in the history and philosophy of science, or in the understanding of the nature of creativity and its relationship to the process of thought.

David Bohm is Emeritus Professor of Theoretical Physics at Birkbeck College, University of London.

\section{From Cambridge to Moscow}

\section{Nevill Mott}

Kapitza, Rutherford, and the Kremlin.

By Lawrence Badash.

Yale University Press: 1985. Pp.129. \$20, $£ 20$.

LAWRENCE Badash has dedicated this book to the memories of Ernest Rutherford (1871-1937) and Peter Kapitza (18941984). The story of the relationship between the two men is well-known. Kapitza, a brilliant young pupil of A.F. Joffe in Leningrad, lost his wife and two children in the influenza epidemic of 1921, and, in an effort to rescue him from his deep grief, friends arranged a trip abroad. They were successful; Kapitza knew where he wanted to go and arrived that year in Rutherford's Cavendish Laboratory. The Mond Laboratory was built for him and a Royal Society chair became his. There he developed equipment for producing strong magnetic fields and low temperatures, work on which was to culminate in the award of a Nobel Prize in 1978. The friendship between the two men must have been very deep, particularly as these branches of physics were far away from Rutherford's beloved nucleus.

Kapitza, as I remember, used to boast that he was the only Soviet citizen whose passport was endorsed for unlimited travel in and out of the Soviet Union. In 1934 he went with his second wife Anna to the congress in Leningrad which celebrated the one-hundreth anniversary of the birth of Mendeleef. They took their car to Bergen, and motored through Norway and Finland. I remember this, as I was invited to the conference, probably because I had helped Frenkel with the English version of his book on liquids, and Kapitza suggested that my wife and I should join them in their car (in the event there seemed not to be enough room for us and the luggage, and we went by boat). Once there, Kapitza was told that his country needed him and he must stay. Anna went back to Cambridge, joining him with the children more than a year later.
In the book Badash tells the story of Rutherford's efforts to help him, reproduces many of Kapitza's agonized letters to his wife and to Rutherford, and records how eventually much of the Cambridge equipment was bought by the Soviet government, and how, two years later, he was able to settle down to work in his new Institute for Physical Problems of the Academy of Science. He had the help of two of his technicians from Cambridge, who spent several years with him in Moscow.

Kapitza's misery in his first year, which might have seriously endangered his health, was not because he was unwilling to work for his country; he always protested that he wanted to. It was because, until the Institute was ready, there was nothing he could do. To be cut off from work was dreadful for him. If he could have returned to Cambridge, supervised the transfer of equipment to Moscow, finished off certain researches and indeed been treated like a loyal Soviet citizen, he would not have complained, or at any rate not so bitterly. But - and this is what made life intolerable - he was given no trust. People were afraid to talk to him and so he had few friends. An official was detailed to look after him, and promised much, but when Kapitza's winter clothes were posted to Moscow from Cambridge he could not even get the parcel through customs without Kapitza having to pay a huge import duty. Kapitza was denied Western newspapers, but letters to and from his wife seemed to get through, as did telephone calls. I was once in R.H. Fowler's house when a call came through from Kapitza, which lasted a very long time. Apparently he could at least do that, and trunk calls must have been cheap.

A letter from Kapitza to Rutherford in the early days of the Institute records vividly the difficulties of doing research at that time under the Soviet system:

You see Soviet industry is growing at a terrific rate and all is done to make its growing organised and well planned, so that all the system of supply and production is also well planned and organised. But the supply of the factory, which is operating according to a definite plan, must be anticipated in details at the beginning of the year, and evidently represents its demands in very large figures. Such a system is indeed quite unsuitable for the supply of laboratories. I have written and spoken to the
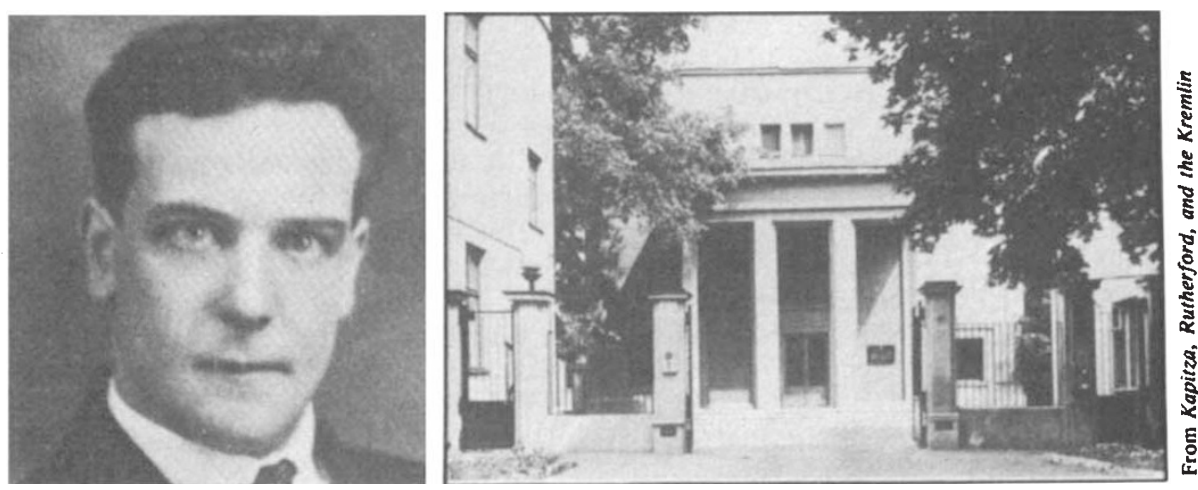

Peter Kapitza (about 1925) and the Institute for Physical Problems, Moscow. 
authorities that the labs must be supplied in a different way, and I think that the people here begin to recognise that the system of supply must be altered for the scientific institutions. But, at present, if for instance we require four bars of phosphor bronze, the need of which we had not anticipated in the beginning of the year, we must get it as an exception and the permission of the sub-secretary of the Heavy Industries is required and this means a lot of correspondence, which is equally extensive if we require 10 kilograms, 10 tons or 10 loads of stuff. And so even if the Institute is given sufficient money, and even if the industries are quite decent, we are actually very badly supplied.

He believed, however, that things would get better. But later he wrote:

My colleagues the scientists are very scared of me and behave like pigs. My institute is attached to the Academy of Science, of which I am not a member but they govern my institute. The president is Karpinsky, he is ninety years old. During meetings of the Council he sleeps with a happy and kind smile on his face.

It is for insights such as these, showing the reactions to Soviet bureaucracy of a great man who had experienced Cambridge, that I recommend this book. Parts of it are compulsive reading. How much the bureaucracy has changed since then is not discussed but in any case Kapitza came to terms with it, became a Hero of Socialist Labour, received several Orders of Lenin and was throughout a sane and courageous voice in Soviet science. One wonders if he would have survived the early days without Rutherford's moral support, and Rutherford's efforts - though unsuccessful - to secure his release, which are here described by Badash. Kapitza repaid some of his debt in his "Recollections of Lord Rutherford", published in the Proceedings of the Royal Society in 1966.

Kapitza, then, was back to work by 1936. The author remarks that the timing was fortunate, for Rutherford, upon whom he depended so much for aid and encouragement, died in October 1937.

Sir Nevill Mott is Emeritus Professor of Physics at the University of Cambridge.
Arrhenius and Mittag-Leffler intervened rather irregularly, but whenever they felt moved to support a personal preference, or to thwart the candidate of a rival, they acted with rare zest.

In this running confrontation, Arrhenius had a notable early success when he saw to it that the first prize in chemistry went to J.H. van't Hoff, whose work on electrolytic phenomena complemented his

\section{Between machination and merit}

\section{Robert Fox}

The Beginnings of the Nobel Institution: The Science Prizes, 1901-1915.

By Elisabeth Crawford.

Cambridge University Press: 1985.

Pp.281. f22.50, \$34.50.

A FEW days after Alfred Nobel's death in December 1896, his close relatives gathered expectantly for the reading of his will. They were in for a shock. For Nobel had bequeathed to his family a mere one million crowns. The rest of his vast estate, amounting to 30 times that amount (over $£ 1 \frac{1 / 2}{2}$ million), was to be invested to provide five annual prizes, for physics, chemistry, medicine or physiology, literature, and what Nobel (a convinced pacifist, despite the fortune he had made from explosives) called "contributions to the fraternity between nations". Predictably, the will was contested. But the adjustment that was made in favour of the family was meagre, and in 1901 the first prizes were awarded essentially in accordance with Nobel's wishes.

Elisabeth Crawford traces the difficult birth of the Nobel system and the labyrinthine processes by which the awards were made in physics and chemistry between 1901 and 1915. The sheer size of the prizes, each of them worth about 30 times the annual salary of a university professor, was enough to ensure intense public interest. And the element of spectacle was further enhanced by national as well as personal rivalries which made it difficult for the brash newcomer to integrate with the rather chaste rèward system of European science as it existed at the beginning of the century. Tradition demanded, of course, that the cruder rivalries should be concealed. But Crawford penetrates this facade to excellent effect. Drawing on her intimate knowledge of the relevant Nobel archives (open since 1974, in accordance with a new 50-year rule) and of the context and content of Swedish science in the early twentieth century, she casts radically new light on the complex interaction between the dispersed international networks of nominators and the subject committees in Sweden.

Few readers will be surprised by Crawford's demonstration of the keen opposition between the various national traditions in science, for, by 1900 , science was emerging as a battle-field on which the European powers were only too ready to try their strength, not least with the disturbing new force in research, the United States. The French, it seems, were especially prone to nominate their fellowcountrymen, far more so than the Germans, who have a commendably low score on Crawford's ingenious index of chauvinism. (Britain's record was mixed, with the physicists appearing distinctly more chauvinistic than the chemists.) However, Crawford's evidence suggests that it was the Swedes themselves who injected the greatest element of competitiveness. Here, the main antagonists were Svante Arrhenius, already distinguished internationally for his work on the theory of solutions, and the mathematician Gösta Mittag-Leffler. The two men were poles apart in their political sympathies and in temperament and lifestyle. Arrhenius was liberal, popular and modest to the point of insecurity about his scientific abilities, whereas Mittag-Leffler was conservative, flamboyant and more respected than liked. As Crawford shows,

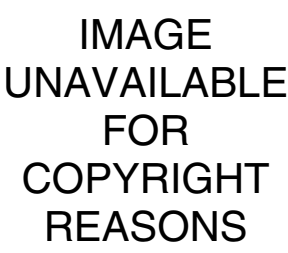

Arrhenius - "modest to the point of insecurity about his scientific abilities...".

own. In 1909, Arrhenius successfully backed another ionist, Wilhelm Ostwald, and; using more negative tactics, he managed to delay an award for his rival Walther Nernst until 1921 (15 years after the first nominations for Nernst had been received). Mittag-Leffler, by contrast, saw his main mission as the advancement of mathematical physics. It was he who secured at least a share in the physics prize for H.A. Lorentz in 1902. And it was only misfortune which denied him his greatest triumph: his long campaign in favour of Poincaré had still not succeeded when Poincaré died in 1912.

These episodes and the intolerance they imply are far from edifying. But generally Crawford's book is reassuring. It provides ample evidence that although animosity, national interest and the stage-managing of nominations all played their part, scientific merit was nevertheless consistently rewarded. It is arguable that a blunder was made in 1908, when the French experimentalist Gabriel Lippmann emerged as a successful compromise candidate, following MittagLeffler's mishandling of his own campaign in favour of a joint award to Planck and Wien. But while Lippmann was no Planck, even this decision rewarded excellence of a kind. Like the overwhelming majority of the decisions discussed by Crawford, it seems a beacon of wisdom when compared, say, with the award of the first prize in literature to the poet Sully Prudhomme as a sop to French pride. All told, the physicists and chemists of Europe and North America come out of this intriguing and well-told story with a good deal of credit. $\square$

Robert Fox is British Academy Reader in the Humanities at the University of Lancaster. 